\title{
Gender differences and relationships between upper extremity muscle strength, lower limb power and shuttle velocity in forehand smash and jump smash in badminton
}

\author{
ANNA FERREIRA $^{1 *}$, MICHAŁ GÓRSKI ${ }^{2}$, JAN GAJEWSKI $^{1}$ \\ ${ }^{1}$ Faculty of Physical Education, Józef Piłsudski University of Physical Education in Warsaw, Poland. \\ ${ }^{2}$ Department of Kinesiology, Institute of Sport - National Research Institute, Warsaw, Poland.
}

\begin{abstract}
Purpose: The aim of the study was to investigate the relationships between shuttlecock velocity during a badminton forehand smash with and without jump ( $V_{\operatorname{maxWJ}}$ and $V_{\operatorname{maxNJ}}$ ), strength of upper limb muscles, vertical jump height and to analyze differences in these parameters for each gender. Methods: The study examined members of the Polish National Badminton Team seven women and seven men. A special torque meter was used to assess the strength of the upper limb muscles. Vertical jumps were performed on an AMTI force plate. Shuttlecock velocity was measured using Vicon motion capture system. Results: Differences between the right and left limbs were observed in all muscle groups except shoulder flexion for both genders. The results of all measured parameters: torques, height of countermovement and spike jump $\left(\mathrm{HA}_{\mathrm{CMJ}}, \mathrm{H}_{\mathrm{CMJ}}, \mathrm{H}_{\mathrm{SPJ}}\right), V_{\max \mathrm{WJ}}$ and $V_{\operatorname{maxNJ}}$, were greater for men than for women. No statistically significant differences were found between $V_{\operatorname{maxWJ}}$ (men: $83.27 \pm 4.83 \mathrm{~m} / \mathrm{s}$; women: $67.57 \pm 4.21 \mathrm{~m} / \mathrm{s}$ ) and $V_{\operatorname{maxNJ}}(\mathrm{men}: 84.19 \pm 6.05 \mathrm{~m} / \mathrm{s}$; women: $69.70 \pm 6.53 \mathrm{~m} / \mathrm{s}$ ) within the same gender. Positive correlations were found between both $\mathrm{H}_{\mathrm{CMJ}}$ and $\mathrm{H}_{\mathrm{SPJ}}$ regarding $V_{\operatorname{maxWJ}}$ in men; the height of shuttlecock impact in jump smash $\left(\mathrm{H}_{\mathrm{WJ}}\right)$ and $\mathrm{H}_{\mathrm{SPJ}}$ in women; proving the importance of jumping ability in badminton. Negative correlations were found between HWJ and $V_{\operatorname{maxWJ}}$ for both genders. Conclusions: The jump before smash is not used in order to hit the shuttle from the highest point, but to gain time to correctly prepare the phase of stroke while being in the air.
\end{abstract}

Key words: biomechanics, shuttlecock speed, technique, badminton players, performance

\section{Introduction}

Badminton is an extremely complex sport that requires a great deal of versatility from the athlete. It is important for the athlete to use a combination of almost all the motor abilities developed at a very high level [1], [20]. In addition to proper technique and tactical skills, other important components of success in badminton include especially agility and jumping abilities, which are necessary during dynamic changes of running direction, often ending with deep lunges or jumps. Jumping also plays an important role in the smash, which is the most common offensive shot in badminton. The goal of this technique is to direct the shuttlecock towards the opponent's field with the highest possible velocity [20], [27] and a falling trajectory [1], [27], [31]. Giving the highest possible velocity to the shuttlecock and directing it at the greatest possible angle downwards allows the athlete to reduce the time for the shuttlecock to cover the distance between the place of impact and the opponent's playing field, which makes it difficult for the opponent to defend against such a shot.

Another element that reflects the sports' skill level in badminton is the player's strength potential. In its movement structure, the smash resembles shots performed in other sports, such as tennis, volleyball or handball [15], [29]. The common element is a dynamic movement of

\footnotetext{
* Corresponding author: Anna Ferreira, Department of Human Biology, Faculty of Physical Education, Józef Piłsudski University of Physical Education in Warsaw, 34 Marymoncka Street, 00-968 Warsaw, Poland. Phone: +48 2283489 40, e-mail: anna.glebocka@interia.pl Received: May 6th, 2020

Accepted for publication: August 11th, 2020
} 
the upper limb above the head, which results in strong braking in the last phase of the movement. Muscle strength is often evaluated by measurements of forces under isokinetic conditions [7], [16]. Although muscle activity under isokinetic conditions differs both mechanically and in neural terms from that performed under isometric conditions [6], there are a number of studies demonstrating the usefulness of isometric force measurements in the assessment of the strength potential of athletes practising sports in which very fast and dynamic movements prevail. Baiget et al. [5] demonstrated a correlation between the maximum values of muscle torques and the velocity of the ball being served in tennis and suggested that the values of isometric muscle torques are an acceptable indicator describing the opportunities for developing the velocity of a tennis service. Gajewski et al. [10] postulated the use of allometry as a tool extending the evaluation of strength potential based on isometric measurements. Furthermore, Baiget et al. [5] noted that there is still a lack of research on the relationship between isometric strength in upper and lower limbs involved in the movement of the entire biokinematic chain.

Few studies have evaluated the values of isometric muscle torques in badminton players. However, the available studies demonstrated a relationship between badminton performance and shoulder strength [24] and the correlation between isometric shoulder strength and racket velocity during the badminton forehand smash movement [4]. Therefore, it seems justified to continuously monitor and evaluate the strength and power generated by badminton players.

The aim of the study was to verify: 1) differences in strength, power generation and shuttlecock velocity that result from the athlete's gender, 2) differences in maximum muscle torques in the joints of the dominant limb (that holding the racket) and the non-dominant limb, 3) the relationship between the jump height estimated using the dynamometric platform and the height of the smash and velocity of the smashed shuttlecock.

\section{Materials and methods}

\section{Participants}

Seven female and seven male right-handed badminton players took part in the study (Table 1). All of them were members of the Polish National Badminton Team. None of them reported any injuries of the upper and lower limb joints for six months prior to the study. All participants were informed about the purpose of the study and signed the consent form before tests. Written informed consent was obtained from all the participants.
Ethical approval for this study was provided by the Senate Research Ethics Committee of the Józef Piłsudski University of Physical Education in Warsaw, Poland. The study was conducted in accordance with the Declaration of Helsinki.

Table 1. Somatic characteristics of badminton players (mean $\pm \mathrm{SD}$ )

\begin{tabular}{|l|c|c|}
\hline & Female $(n=7)$ & Male $(n=7)$ \\
\hline Age [years] & $22.71 \pm 4.23$ & $24.71 \pm 3.73$ \\
\hline Body mass [kg] & $59.84 \pm 6.68$ & $77.27 \pm 4.72$ \\
\hline Body height [cm] & $163.89 \pm 7.44$ & $184.76 \pm 7.11$ \\
\hline Training practice [years] & $13.43 \pm 4.86$ & $15.00 \pm 3.06$ \\
\hline
\end{tabular}

\section{Measurement}

All measurements were performed after the standard warm-up in the Laboratory of Biomechanics at the Institute of Sport - National Research Institute, Warsaw, Poland. in the following order: measurements of the height of vertical jumps on the force plate, recording of shuttle's velocity and height of hit, measurements of maximum muscle torque under isometric conditions.

\section{Power output and height of jump}

The height of the rise of the body centre of mass $(\mathrm{COM})$ and the power of lower extremities during vertical jumps were measured using a Kistler force plate type 9281A (Kistler Instrumente AG Winterthur, Switzerland) with the Kistler amplifier Type 9865 B 1 Y28 (Kistler Instrumente AG Winterthur Switzerland), connected to a computer via an A/D converter was used for measurements. Maximum height of rise of the body's COM $(h[\mathrm{~m}])$, absolute peak power $\left(P_{\max }[\mathrm{W}]\right)$ and relative peak power $\left(P_{\max } \cdot \mathrm{m}^{-1}\left[\mathrm{~W} \cdot \mathrm{kg}^{-1}\right]\right)$ were calculated from the recorded ground reaction force using the MVJ v. 3.4 software package ("JBA" Zb. Staniak, Poland). Each participant performed nine vertical jumps on the force plate: three jumps of each kind. The characteristics of each jumping test were as follows [11]:

- ACMJ - akimbo countermovement jump - a vertical jump from an upright standing position with hands on the hips (position akimbo) and countermovement of the COM before the take-off;

- CMJ - countermovement jump - a vertical jump from a standing erect position, preceded by an arm-swing and countermovement of the body COM before the take-off;

- SPJ - a vertical jump which is performed with a 3-4-step run-up before the take-off. The participant's task was to take off and land on the platform.

The participants were asked to jump as high as possible in each trial. There were 5 -second breaks between 
each ACMJ and CMJ jump and 1-min breaks between the SPJs. There was a 1-min break between each series of jumps as well. The jump with the highest elevation of the body's COM was chosen for statistical analysis.

\section{Muscle strength (maximal joint torque)}

The maximal joint torque (JT) of the flexors and extensors of the elbow and shoulder were measured under isometric conditions, using a special torque meter (Institute of Sport, Poland; type SMS1 (upper extremities)). During the measurements of elbow flexors and extensors, the subject was in a sitting position, with his arm and forearm positioned to a $90^{\circ}$ angle and placed on the armrest, and with the trunk stabilized. The joint torque of the shoulder flexors and extensors was also measured in a sitting position. The flexion angle was set at $70^{\circ}$ and the extension angle was $50^{\circ}$. The maximal extension of the elbow was accepted as $0^{\circ}$. For the shoulder joint, the position of the arm along the side of the body was taken as $0^{\circ}$. The axis of rotation during joint torque measurements corresponded to the axis of rotation of the torque meter. Joint torques of the right and left limb were measured separately, always in the order flexion-extension. The subjects were instructed to develop maximal possible force. The total error in the measurement of the maximal torque did not exceed $4 \%$. The maximal error of repeatability, expressed by the coefficient of variation, was $4.2 \%$ [10].

\section{Shuttle velocity and height of hit}

A colourful string was placed so that it was visible for the athlete at the height of $30 \mathrm{~cm}$ over the net, which was placed at the standard height of $155 \mathrm{~cm}$. In order to ensure the repeatability of the measurement conditions, the shuttlecock was played by the Leopard Smart shuttlecock throwing machine during the performance of the smash (Fig. 1). The athlete's task was to perform such a shot that the shuttlecock flew between the net and the coloured string, giving the shuttlecock the highest possible velocity. The athletes performed the smash using their own rackets (strung according to the individual athlete's preferences) until 5 accurate jump shots and 5 accurate shots without jumps were recorded. Rests between the attempts were administered at the request of the athlete. The smashes in which the shuttlecock was given the highest velocity were used for further analysis (the fastest jump smash and the fastest no jump smash of each player).

The measurements were taken with the Vicon motion capture system equipped with ten MX T40S cameras sampling at $200 \mathrm{~Hz}$, two reference Bonita cameras $(50 \mathrm{~Hz})$, a power and synchronization device (Giganet) and Nexus v.1.9.1 software. Retroreflective tape was placed on the shuttle (Fig. 1). Height of hit ( $H_{\mathrm{WJ}}$ and $H_{\mathrm{NJ}}$ for jump smash and no jump smash, respectively) and shuttle velocity $\left(V_{\operatorname{maxWJ}}\right.$ and $\left.V_{\operatorname{maxNJ}}\right)$ were determined based on the estimated coordinates. Shuttle trajectory was filtered at $100 \mathrm{~Hz}$ using a fourth-order low-pass Butterworth digital filter (zero lag) and processed with Nexus software.

\section{Statistical analysis}

Analysis of variance (ANOVA) for repeated measures was used to compare joint torques between the left and right extremity in male and female athletes. The significance of differences between means
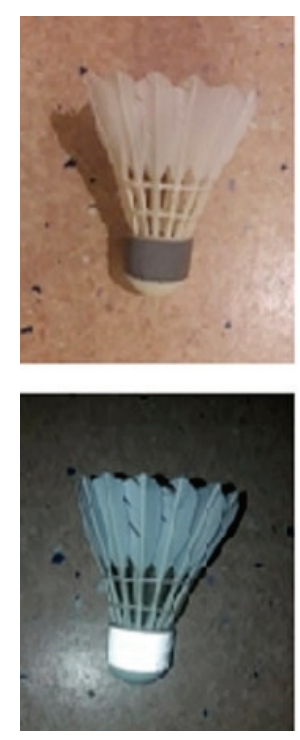

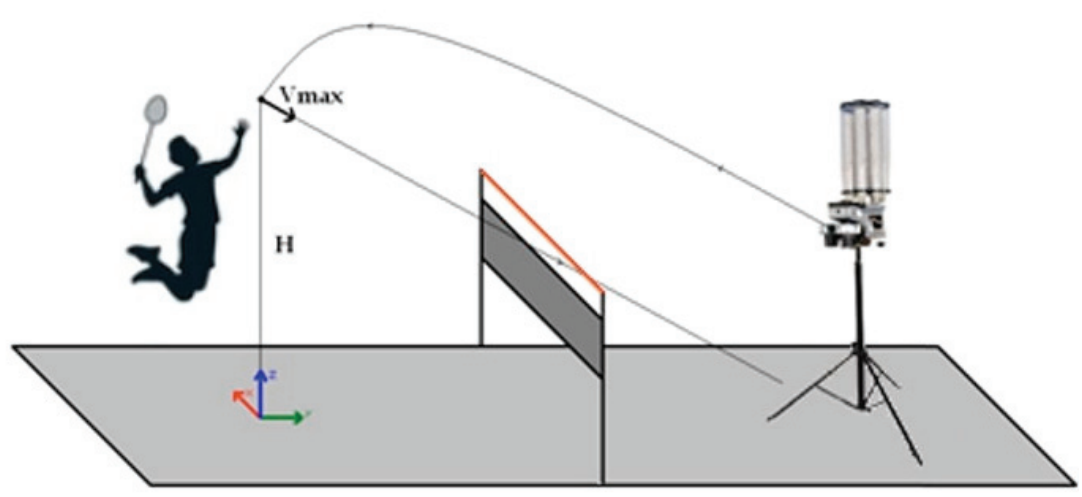

Fig. 1. Shuttlecock with reflective marker and the athlete during the attempt of smashing the shuttlecock played by the Leopard Smart throwing machine 
was evaluated using Tukey's post-hoc test. Analysis of covariance (ANCOVA) was employed to compare maximum shuttle velocity in men and women taking the height of hit during the jump smash and no jump smash into consideration. Effect size was estimated using partial $\eta^{2}$. Relationships between all variables were assessed by calculating Pearson's linear correlation coefficients. Simple comparisons between male and female group were done using Mann-Whitney $U$-test. The thresholds used to qualitatively assess the correlations (or $\eta$ ) were based on Hopkins [13], using the following criteria: $<0.1$ - trivial; 0.1 to 0.3 - small; 0.31 to 0.5 - moderate; 0.51 to 0.7 - large; 0.71 to 0.9 - very large; $>0.91$ - nearly perfect. For the statistical analyses, the value of $p<0.05$ was considered significant. All computations were performed with STATISTICA software (v. 12.0, StatSoft, USA).

\section{Results}

In Table 2, the results of measurements of maximal muscle torques developed under isometric conditions are illustrated. Women achieved significantly lower values of maximum muscle torques in all measurements compared to men.

Significant differences between the right (dominant) and left (non-dominant) limbs were observed in all muscle groups except shoulder flexion for both male and female athletes (Table 2). This asymmetry was more pronounced in elbow extension for men (significant interaction Gender $\times$ Side). No correlation was found between the values of muscle torques and the velocity of the shuttlecock during the performance of the jump smash and no jump smash.

The results of the jumping test are contained in Table 3. Women achieved lower results compared to men in all measured parameters.

The linear velocity given to the shuttlecock and the height of the shuttlecock impact during the smash jump and the standing smash are presented in Table 4. Men smashed the shuttlecock from a greater height, giving it a higher linear velocity in both examined shots. However, no statistically significant differences were found between $V_{\operatorname{maxwJ}}$ and $V_{\operatorname{maxNJ}}$ within the groups.

The graphs below show the relationships between the linear velocity of the shuttlecock during the jump smash and the height of the rise of the centre of gravity in the CMJ and SPJ jumps in men (Fig. 2: diagrams (a) and (b)). Diagram (c) shows the relation between the height of the jump in the SPJ and the height at which the shuttlecock was struck $\left(H_{\mathrm{WJ}}\right)$ during the jump smash in women. Diagram (d) illustrates an negative relationship between the height at which the shuttlecock was hit $\left(H_{\mathrm{WJ}}\right)$ and the velocity given to the shuttlecock during the jump smash in women and men. ANCOVA confirmed a strong relationship between $V_{\text {maxWJ }}$ and $H_{\mathrm{WJ}}\left(F_{1,11}=23.5, p<0.001, \eta^{2}=0.681\right)$ as well as gender $\left(F_{1,11}=100.6, p<0.001, \eta^{2}=0.901\right)$. Correlation between $V_{\operatorname{maxWJ}}$ and $H_{\mathrm{WJ}}$ was negative and amounted $r=-0.832$ and $r=-0.829$ for women and men, respectively.

Table 2. Relative \pm SD value of muscle torque for: ELF-R - elbow flexion of right limb, ELF-L - elbow flexion of left limb, ELE-R - elbow extension of right limb, ELE-L - elbow extension of left limb, SF-R - shoulder flexion of right limb, SF-L - shoulder flexion of left limb, SE-R - shoulder extension of right limb, SE-L - shoulder extension of left limb, UE-R - sum for right upper extremity, UE-L - sum for left upper extremity

\begin{tabular}{|c|c|c|c|c|c|c|}
\hline & Female $(n=7)$ & Male $(n=7)$ & Factor & $F_{1.12}$ & $p$ & $\eta^{2}$ \\
\hline ELF-R [Nm/kg] & $0.67 \pm 0.02$ & $0.96 \pm 0.10$ & \multirow{2}{*}{$\begin{array}{l}\text { Gender: } \\
\text { Side: } \\
\text { Gender } \times \text { Side: }\end{array}$} & \multirow{2}{*}{$\begin{array}{c}\mathbf{5 8 . 4 2} \\
\mathbf{1 3 . 9 9} \\
3.38 \\
\end{array}$} & \multirow{2}{*}{$\begin{array}{l}<0.001 \\
\mathbf{0 . 0 0 2 8} \\
0.0911\end{array}$} & \multirow{2}{*}{$\begin{array}{l}\mathbf{0 . 8 3 0} \\
\mathbf{0 . 5 3 8} \\
0.220\end{array}$} \\
\hline ELF-L $[\mathrm{Nm} / \mathrm{kg}]$ & $0.64 \pm 0.05$ & $0.88 \pm 0.08$ & & & & \\
\hline ELE-R [Nm/kg] & $0.45 \pm 0.05$ & $0.72 \pm 0.06^{* \&}$ & \multirow{2}{*}{$\begin{array}{l}\text { Gender: } \\
\text { Side: } \\
\text { Gender } \times \text { Side: }\end{array}$} & \multirow{2}{*}{$\begin{array}{l}106.8 \\
22.76 \\
12.16\end{array}$} & \multirow{2}{*}{$\begin{array}{l}<0.001 \\
<0.001 \\
0.0045\end{array}$} & \multirow{2}{*}{$\begin{array}{l}0.899 \\
0.655 \\
0.503\end{array}$} \\
\hline ELE-L $[\mathrm{Nm} / \mathrm{kg}]$ & $0.43 \pm 0.04$ & $0.60 \pm 0.04^{*}$ & & & & \\
\hline SF-R $[\mathrm{Nm} / \mathrm{kg}]$ & $0.72 \pm 0.09$ & $0.83 \pm 0.12$ & \multirow{2}{*}{$\begin{array}{l}\text { Gender: } \\
\text { Side: } \\
\text { Gender } \times \text { Side } \\
\end{array}$} & \multirow{2}{*}{$\begin{array}{c}\mathbf{1 0 . 7 9} \\
2.04 \\
1.82\end{array}$} & \multirow{2}{*}{$\begin{array}{l}\mathbf{0 . 0 0 6 5} \\
0.1785 \\
0.2020\end{array}$} & \multirow{2}{*}{$\begin{array}{l}\mathbf{0 . 4 7 4} \\
0.145 \\
0.132\end{array}$} \\
\hline SF-L $[\mathrm{Nm} / \mathrm{kg}]$ & $0.62 \pm 0.08$ & $0.82 \pm 0.13$ & & & & \\
\hline SE-R [Nm/kg] & $0.84 \pm 0.13$ & $1.06 \pm 0.14$ & \multirow{2}{*}{$\begin{array}{l}\text { Gender: } \\
\text { Side: } \\
\text { Gender } \times \text { Side }\end{array}$} & \multirow{2}{*}{$\begin{array}{l}\mathbf{1 2 . 1 3} \\
\mathbf{8 . 5 0} \\
0.02\end{array}$} & \multirow{2}{*}{$\begin{array}{l}\mathbf{0 . 0 0 4 5} \\
\mathbf{0 . 0 1 2 9} \\
0.8667\end{array}$} & \multirow{2}{*}{$\begin{array}{l}\mathbf{0 . 5 0 3} \\
\mathbf{0 . 4 1 5} \\
0.002\end{array}$} \\
\hline SE-L $[\mathrm{Nm} / \mathrm{kg}]$ & $0.78 \pm 0.10$ & $1.00 \pm 0.13$ & & & & \\
\hline UE-R [Nm/kg] & $2.67 \pm 0.20$ & $3.56 \pm 0.31$ & \multirow{2}{*}{$\begin{array}{l}\text { Gender: } \\
\text { Side: } \\
\text { Gender } \times \text { Side }\end{array}$} & \multirow{2}{*}{$\begin{array}{c}\mathbf{5 4 . 1 1} \\
\mathbf{2 2 . 1 3} \\
0.52 \\
\end{array}$} & \multirow{2}{*}{$\begin{array}{l}<\mathbf{0 . 0 0 1} \\
<\mathbf{0 . 0 0 1} \\
0.4840\end{array}$} & \multirow{2}{*}{$\begin{array}{l}\mathbf{0 . 8 1 8} \\
\mathbf{0 . 6 4 8} \\
0.042\end{array}$} \\
\hline UE-L [Nm/kg] & $2.48 \pm 0.21$ & $3.30 \pm 0.21$ & & & & \\
\hline
\end{tabular}

* - statistically significant difference vs. females, $p<0.001,{ }^{\&}$ - statistically significant difference vs. left side, $p<0.001$. 
Table 3. Mean values $( \pm \mathrm{SD})$ of the height of rise of the body centre of mass $(H)$, peak power output $\left(P_{\max }\right)$, relative peak power output $\left(P_{\max } \cdot \mathrm{BM}-1\right)$

during akimbo countermovement jumps (ACMJ), countermovement jumps (CMJ) and spike jumps (SPJ) on the force plate

\begin{tabular}{|l|c|c|}
\hline & Female $(n=7)$ & Male $(n=7)$ \\
\hline$H_{\text {ACMJ }}[\mathrm{cm}]$ & $30.79 \pm 3.53$ & $45.47 \pm 2.00^{*}$ \\
\hline$H_{\mathrm{CMJ}}[\mathrm{cm}]$ & $36.46 \pm 3.75$ & $50.24 \pm 3.33^{*}$ \\
\hline$H_{\mathrm{SPJ}}[\mathrm{cm}]$ & $42.51 \pm 1.52$ & $62.57 \pm 2.99^{*}$ \\
\hline$P_{\operatorname{maxACMJ}}[\mathrm{W}]$ & $1286 \pm 279$ & $2473 \pm 265^{*}$ \\
\hline$P_{\operatorname{maxCMJ}}[\mathrm{W}]$ & $1664 \pm 257$ & $3206 \pm 451^{*}$ \\
\hline$P_{\operatorname{maxSPJ}}[\mathrm{W}]$ & $2211 \pm 411$ & $4754 \pm 696^{*}$ \\
\hline$P_{\operatorname{maxACMJ}} / \mathrm{BM}[\mathrm{W} / \mathrm{kg}]$ & $21.43 \pm 3.95$ & $32.12 \pm 3.88^{*}$ \\
\hline$P_{\operatorname{maxCMJ}} / \mathrm{BM}[\mathrm{W} / \mathrm{kg}]$ & $27.74 \pm 2.52$ & $41.41 \pm 4.13^{*}$ \\
\hline$P_{\operatorname{maxSPJ}} / \mathrm{BM}[\mathrm{W} / \mathrm{kg}]$ & $36.77 \pm 4.62$ & $61.69 \pm 9.44^{*}$ \\
\hline
\end{tabular}

* - statistically significant differences vs. females $(p<0.001)$.
$H_{\mathrm{WJ}}$ proved to be related rather to body height $\left(F_{1,10}=6.48, p=0.0291, \eta^{2}=0.393\right)$ than to height of SPJ jump $\left(F_{1,10}=0.024, p=0.8794, \eta^{2}=0.002\right)$ or gender $\left(F_{1,10}=1.21, p=0.2978, \eta^{2}=0.108\right)$. A positive correlation was observed between body height and $H_{\mathrm{WJ}}$ in female athletes $(r=0.863)$.

\section{Discussion}

During a badminton smash, the muscle groups that control the movement of the upper limb are responsible for dynamic propulsion of the racket and the effective deceleration of the biokinematic chain after the hit. This phenomenon has been observed in many sports with similar movement structure, such as tennis, vol-

Table 4. Mean values $( \pm \mathrm{SD})$ of the shuttle's maximum velocity $(V \max )$ and height of hit $(H)$ during smash with jump (WJ) and with no jump (NJ)

\begin{tabular}{|c|c|c|c|c|c|c|}
\hline & Female $(n=7)$ & Male $(n=7)$ & Factor & $F_{1,12}$ & $p$ & $\eta^{2}$ \\
\hline$H_{\mathrm{WJ}}[\mathrm{m}]$ & $2.44 \pm 0.13 \#$ & $2.88 \pm 0.11 * \#$ & \multirow{2}{*}{$\begin{array}{l}\text { Gender: } \\
\text { Jump: } \\
\text { Gender } \times \text { Jump }\end{array}$} & 42.65 & $<0.001$ & 0.780 \\
\hline$H_{\mathrm{NJ}}[\mathrm{m}]$ & $2.31 \pm 0.10$ & $2.59 \pm 0.11^{*}$ & & $\begin{array}{l}103.6 \\
16.02\end{array}$ & $\begin{array}{l}<0.001 \\
0.0018 \\
\end{array}$ & $\begin{array}{l}0.896 \\
0.572 \\
\end{array}$ \\
\hline$V_{\operatorname{maxWJ}}[\mathrm{m} / \mathrm{s}]$ & $67.57 \pm 4.21$ & $83.27 \pm 4.83^{*}$ & \multirow{2}{*}{$\begin{array}{l}\text { Gender: } \\
\text { Jump: } \\
\text { Gender } \times \text { Jump }\end{array}$} & \multirow{2}{*}{\begin{tabular}{c|}
$\mathbf{6 9 . 7 2}$ \\
0.13 \\
0.403 \\
\end{tabular}} & \multirow{2}{*}{$\begin{array}{l}<\mathbf{0 . 0 0 1} \\
0.7222 \\
0.5374 \\
\end{array}$} & \multirow{2}{*}{$\begin{array}{l}\mathbf{0 . 8 5 3} \\
0.010 \\
0.033 \\
\end{array}$} \\
\hline$V_{\operatorname{maxNJ}}[\mathrm{m} / \mathrm{s}]$ & $69.70 \pm 6.53$ & $84.19 \pm 6.05 *$ & & & & \\
\hline
\end{tabular}

* - statistically significant differences vs. females $(p<0.001)$; \#- statistically significant differences vs. $H_{\mathrm{NJ}}(p<0.001)$.

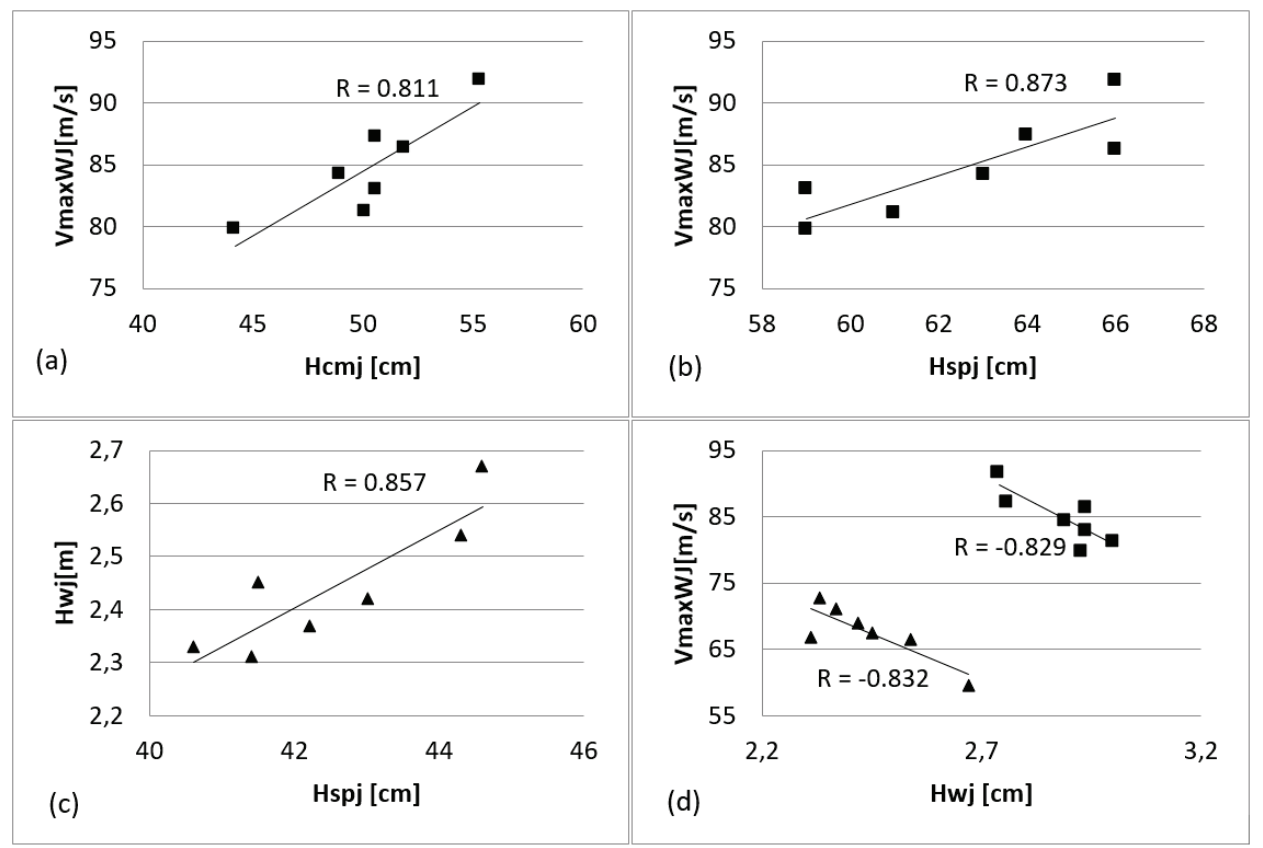

Fig. 2. Spearman correlation between: (a) linear velocity given to the shuttlecock as a result of the shot during the jump smash and the height of rise of the centre of gravity in the CMJ jump in men; (b) linear velocity given to the shuttlecock as a result of the shot during the jump smash and the height of rise of the centre of gravity in the SPJ jump in men;

(c) height of shuttlecock impact during the smash jump and the height of rise of the centre of gravity in the SPJ jump in women; (d) velocity given to the shuttlecock during the jump smash and the height of shuttlecock impact in women (triangle) and men (squares) 
leyball [29] and baseball [30]. The acceleration stage requires well-coordinated and synchronized work of many muscles of the upper limb and depends on their strength [16]. In our study, differences between the right and left limbs were observed in all muscle groups, except for shoulder flexion, for both male and female athletes. During training sessions, the dominant limb is involved in the permanent repetition of dynamic movements with an additional load in the form of a badminton racket. It is possible that this may have been an additional stimulus for the development of muscle strength to dominant limb. Popieluch et al. [21] examined the strength of the rotator cuff muscles in second-league volleyball players and also found statistically significant differences between the dominant and non-dominant upper limbs. Peak torque values in isometric conditions were higher for the right limb than the left one both in external and internal rotation in both horizontal and vertical positions of the forearm $(p<0.05)$. It can be presumed that volleyball training, in which the attack is similar to that in badminton, and is also performed using the dominant upper limb, represents a sufficient stimulus to develop higher values of maximum muscle torques between the right and left upper limbs. It seems critical to recommend regular control of the level of asymmetry of the dominant and non-dominant sides in all athletes, but especially in athletes practising one-sided sports (e.g., javelin throw, badminton, tennis, fencing, golf) in order to prevent possible injuries and overloads resulting from the uneven load on the musculoskeletal system.

In the assessment of the strength potential of athletes, one should also take into account the method of performing measurements. No studies with badminton players were found to evaluate strength potential using a method similar to that used in our study. However, this measurement method was used in the assessment of strength abilities of athletes from other sports. The results obtained in our study of relative muscle torques of elbow flexors and extensors in the badminton male players were similar to those of basketball players [8] and combat sports athletes [9], [18]. Muscle torques in men developed by the shoulder joint (flexion and extension) were similar to those achieved by combat sports athletes studied by Buśko [9], but were significantly lower than the values recorded in combat sports athletes examined by Pędzich (badminton athletes: $0.82-1.06 \mathrm{Nm} / \mathrm{kg}$ vs. $1.30-1.62 \mathrm{Nm} / \mathrm{kg}$ in taekwondo athletes and boxers) [18]. The values of the sum of muscle torques of flexors and extensors in the elbow and shoulder in men were similar to those developed by teenage handball players [12], but lower than those of taekwondo athletes and boxers (badminton players: $3.30-3.56 \mathrm{Nm} / \mathrm{kg}$ vs. $4.58-4.94 \mathrm{Nm} / \mathrm{kg}$ in taekwondo athletes and boxers) [18]. According to Baiget et al. [5], isometric strength may be an acceptable indicator of athletes' abilities, but there is still a shortage of papers using this measurement method in the literature.

In our research, there was no significant correlation between relative value of muscle torque and shuttle velocity during the smash. By contrast, Awanti et al. [4] obtained a correlation between isometric shoulder strength and racket velocity during the badminton forehand smash movement [4] (racket velocity and the internal rotation torque of the shoulder in the abducted and external rotated position). However, in studies conducted by Awanti [4], the study group contained 5 men and 9 women as one homogeneous group. It means that the correlation could be confounded by gender. Ariff et al. [3] emphasise that during the smash the force on the upper limb is gained from the lower limb during take-off and it is transferred from the shoulder joint to the elbow joint, which influences the velocity of the racket and acceleration of the shuttlecock. Future studies should, therefore, be extended by adding measurements of the strength of the lower limbs.

The results obtained in our study for the height of the rise of the body centre of mass (COM) and the power of lower extremities during vertical jumps are comparable with results obtained by other researchers who examined badminton players from different countries. Ooi et al. [17], in their research on 12 male elite and 12 male sub-elite Malaysian badminton players, acquired respectively 46.3 and $46.0 \mathrm{~cm}$ on average in the vertical jump conducted during the study using the same method as ACMJ used in our paper. Although Polish male players obtained on average $45.47 \mathrm{~cm}$, a big difference in generated power is noticeable between players from Poland and Malaysia (Polish: 2473 W vs. 3977 W (elite) and 3448 W (subelite)). The results similar to ours in height of vertical jump in women were obtained by Abian-Vicen et al. [2], who measured 24 women and 46 men before and after a single game performed during the National Spanish Badminton Championship. Spanish female athletes in the jump conducted with the same method as ACMJ used in our paper, achieved on average $29 \mathrm{~cm}$ (before the match) and $30 \mathrm{~cm}$ (after the match) (vs. Polish $30.8 \mathrm{~cm}$ ). Surprisingly, relative power (related to body mass) of the jump was greater for Spanish women (26.36 and $27.25 \mathrm{~W} / \mathrm{kg}$ vs. Polish $21.43 \mathrm{~W} / \mathrm{kg})$. Identically as in our research, Spanish male players 
had higher results than female players, but, on the other hand, slightly lower than the results of Polish male players (39 and $41.5 \mathrm{~cm}$ vs. Polish $45.47 \mathrm{~cm}$ ) and similar relative power (31.82 and $32.90 \mathrm{~W} / \mathrm{kg}$ vs. Polish $32.12 \mathrm{~W} / \mathrm{kg}$ )

The velocity of the smashed shuttlecock is affected not only by the strength potential of the players but also by the way of performing the strike. Tsai et al. [26] noted that during the jump smash, activation of the muscles involved in the movement measured by means of surface electromyography is greater than that observed in the standing smash. According to Lee [15], during the flight, the mobility of the freed lower limbs increases, which, in turn, allows for better utilization of the transfer of velocity throughout the kinematic chain (the kinematic link principle). According to Phomsoupha and Laffaye [19] and Zhang et al. [31], players with longer training experience are able to smash the shuttlecock at a higher velocity, using a more effective technique developed during the training process.

The lack of statistically significant differences between the velocity of the shuttlecock hit during the jump smash and the standing smash in our study is consistent with studies published by Tsai et al. [25], [26] and Abdurrahman et al. [1]. The results of the female athletes in our study were slightly higher compared to those presented in a study by Tsai et al. [27] $(59.6 \mathrm{~m} / \mathrm{s}$ vs. Polish athletes $69.70 \mathrm{~m} / \mathrm{s})$. The results of Polish men $(84.19 \mathrm{~m} / \mathrm{s})$ were significantly higher than the average values achieved in the athletes examined by Hussain and Bari [14] $(67 \mathrm{~m} / \mathrm{s})$, Rambely and Abas [23] $(57.4 \mathrm{~m} / \mathrm{s})$, and Tsai et al. [26] $(75 \mathrm{~m} / \mathrm{s})$, and comparable to those documented by Abdurrahman et al. [1] $(68.3-93.7 \mathrm{~m} / \mathrm{s})$. The higher results obtained in our study may be the result of the continuous development of the sport and technology used during the training process. With the continuous improvement of training methods and equipment, badminton athletes are able to improve their sports skill level.

It is also noteworthy that the demonstrated strong relationship between $V_{\max }$ and body height and gender shows that taller athletes achieve smaller $V_{\operatorname{maxwJ}}$, but still the relationship with gender is stronger since taller men are still able to smash more strongly than tall women.

The correlation obtained in our study in men between $V_{\operatorname{maxWJ}}$ and $H_{\mathrm{CMJ}}, V_{\max \mathrm{xJ}}$ and $H_{\mathrm{SPJ}}$, in women between $H_{\mathrm{WJ}}$ and $H_{\mathrm{SPJ}}$, and the inverse correlation between $H_{\mathrm{WJ}}$ and $V_{\text {maxws }}$ in men and women (Fig. 2) emphasize the importance of jumping ability in badminton. The negative correlation proves that the jump before a smash is not used in order to hit the shuttle from the highest point, but to gain time to correctly prepare the phase of stroke while being in the air. Similarly, Waddel and Gowitzke [28] found that contact with the shuttle during the smash was performed during the last part of the air phase while the body was descending from its high point. Rambely et al. [22] in his paper after acquiring no correlation between height of the jump during the smash and shuttle velocity ascertained that analysis of the tactic and technique may be able to explain the phenomenon of performing the smash strike. It can be presumed that the real goal of a jump preceding a smash is not to hit the shuttlecock at the greatest possible height or to increase the velocity of the shuttlecock because the velocities of a smash with and without a jump were comparable. It seems that the jump is primarily intended to increase the angle at which the shuttlecock is directed, thus shortening its route and time before landing on the other side of the court and making it difficult for the opponent to perform an effective defence. The authors of other studies have shown that although more experienced players hit the shuttlecock from a height similar to that of amateurs, they are able to direct it at a significantly greater angle [31]. Additionally, it increases the amount of possibilities of placing the shuttle in different parts of the opponent's court than when hitting the shuttle with a flatter angle.

It seems that the smashing technique using the stretch-shortening cycle requires an extension of the time of arm swing which takes place during the flight phase of the jump. Therefore, a higher jump allows the athlete to perform a broader arm swing. Furthermore, during the shot, the athlete transfers kinetic energy related to decreasing the body's centre of mass to the shuttlecock.

In contrast to men, the frequent non-performance of a jump preceding a smash observed during women's competitions may be due to poorer jumping abilities (Table 3) and endurance of women. The pre-smash jump is highly energy-consuming, which may cause women to make a tactical decision not to jump in order to maintain a high game pace.

The main limitation of the present study is the small number of the subjects being tested. On the other hand, all subject were elite athletes, members of the Polish National Team. We believe that the results obtained from such a homogenous group may be useful for explanation of relationships between variables describing a smash technique on the highest level, especially because of large effect sizes of the relationships confirmed. 


\section{Conclusions}

This study attempted to assess the motor abilities of members of the Polish National Badminton Team. In our opinion, although the level of motor abilities in the players studied is at a good level, there is still room for improvement. The evaluation of the potential of female players is difficult because of the poor literature in this area. It seems that further improvement in the sports skill level of the national team members should place emphasis on technical and tactical skills while maintaining the developed good level of motor abilities.

Further examinations of the smash should be aimed to improve knowledge of the details of the technique of performing this shot. The observation should be deepened with the analysis of angles and angular velocities in the upper and lower limbs and body trunk, the height of the centre of gravity at shuttlecock impact, the analysis of the flight phase of the jump and the angle of the shuttlecock after the impact, taking into account differences that may occur due to gender and motor abilities of players. A clear explanation of how a smash is performed could contribute to the development of an effective training plan allowing for the correct and effective improvement of the badminton smash.

\section{Acknowledgements}

Financial support: Project DM-61 implemented at the Józef Piłsudski University of Physical Education in Warsaw, Poland. DSN Scientific project implemented under contract No. 18/07/104.06/ 2019/WIN at the Institute of Sport - National Research Institute, Warsaw, Poland.

\section{References}

[1] Abdurrahman M.R., Miller R., Mcerlain-Naylor S.A., HiLeY M.J., King M.A., Consistency in the badminton jump smash, Kuala Lumpur World Badminton Federation, 2016, 1-12.

[2] Abián-Vicén J., Del Coso J., GonzÁlez-Millán C., SAlINERO J.J., ABIÁN P., Analysis of dehydration and strength in elite badminton players, Plos one, 2012, 7 5), 1-8, e37821.

[3] ARIFF F.H.M., RAmBelY A.S., Determination of torques at upper limb joints during jumping in badminton smash via Kane's method, ISBS - Conference Proceedings Archive, 2008, 73-76.

[4] Awatani T., Morikita I., Urata T., Shinohara J., TAtsumi Y., Correlation between isometric shoulder strength and racket velocity during badminton forehand smash movements: study of valid clinical assessment methods, J. Phys. Ther. Sci., 2018, $30(6), 850-854$.

[5] Baiget E., Corbi F., Fuentes J.P., Fernández-Fernández J., The relationship between maximum isometric strength and ball velocity in the tennis serve, J. Hum. Kinet., 2016, 53 (1), 63-71.
[6] Bazyler C.D., Beckham G.K., Sato K., The use of the isometric squat as a measure of strength and explosiveness, J. Strength Cond. Res., 2015, 29, 1386-1392.

[7] Borms D., MaEnhout A., CoOLs A.M., Upper quadrant field tests and isokinetic upper limb strength in overhead athletes, J. Athl. Training, 2016, 51 (10), 789-796.

[8] BuśKo K., Training-induced changes in the topography of muscle torques and maximal muscle torques in basketball players, Biol. Sport, 2012, 29, 77-83.

[9] Buśко K., Comparison of muscle strength in male combat sport athletes, Polish J. Sport Tour, 2016, 23 (4), 186-189.

[10] Gajewski J., Buśko K., Mazur J., Michalski R., Application of allometry for determination of strength profile in young female athletes from different sports, Biol. Sport, 2011, 28 (4), 239-243.

[11] Gajewski J., Michalski R., BuŚKo K., MazuR-RÓżycka J., STANIAK Z., Countermovement depth - a variable which clarifies the relationship between the maximum power output and height of a vertical jump, Acta Bioeng. Biomech., 2018, 20 (1), 127-134.

[12] Górski M., Starczewski M., Pastuszak A., Mazur-RÓżYCKA J., GAJEWSKi J., BuŚKO K., Changes of strength and maximum power of lower extremities in adolescent handball players during a two-year training cycle, J. Hum. Kinet., 2018, 63 (1), 95-103.

[13] Hopkins W.G., A Scale of Magnitudes for Effect Statistics, A New View of Statistics. 2002, Available at: URL: http:// www.sportsci.org/resource/stats/effectmag.html, accessed on 15.05.2019.

[14] HuSSAIN I., BARI M.A., Kinematical analysis of forehand and backhand smash in badminton, Innovative Systems Design and Engineering, 2011, 2 (7), 20-25.

[15] LEE B.K., The effect of the kinematic link principle on performance, Biomechanics in Sports XI, 1993, 239-242.

[16] NG G.Y.F., LAM P.C.W., A study of antagonist/agonist isokinetic work ratios of shoulder rotators in men who play badminton, J. Orthop. Sport Phys., 2002, 32 (8), 399 $-404$.

[17] Ooi C.H., Tan A., Ahmad A., Kwong K.W., Sompong R., Ghazali K.A., Liew S.L., Chai W.J., Thompson M.W., Physiological characteristics of elite and sub-elite badminton players, J. Sport Sci., 2009, 27 (14), 1591-1599.

[18] Pędzich W., Mastalerz A., Sadowski J., Estimation of muscle torque in various combat sports, Acta Bioeng. Biomech, 2012, 14 (4), 107-112.

[19] Phomsoupha M., Laffaye G., Shuttlecock velocity during a smash stroke in badminton evolves linearly with skill level, Comput. Method Biomec., 2014, 17, 140-141.

[20] Phomsoupha M., Laffaye G., The science of badminton: game characteristics, anthropometry, physiology, visual fitness and biomechanics, Sports Med., 2015, 45 (4), 473-495.

[21] Popieluch A., StaniszewsKi M., Wychowański M., Strength of the Shoulder Rotators in Second-League Volleyball Players, Polish J. Sport Tour, 2015, 22 (4), 215-218.

[22] Rambely A.S., ABAS W.A.B.W., YusOF M.S., The analysis of the jumping smash in the game of badminton, ISBS - Conference Proceedings Archive, 2005, 671-674.

[23] Rambley A.S., ABas W.A.B.W., Contact time and take-off speed relationship in determining height of jump in jumping badminton smash, ISBS - Conference Proceedings Archive, 2008, 661-663.

[24] Tiwari M.L., Rai V., SRinet S., Relationship of selected motor fitness components with the performance of badmin- 
ton player, Asian J. Phys. Educ. Comput. Sci. Sport, 2011, $5,88-91$.

[25] Tsai C.L., Huang C.F., Chang S.S., Lai C.M., Biomechanical analysis between badminton standing smash and jumping smash in the different target setup, International Society of Biomechanics Xlxth Congress, Book of Abstracts, Dunedin, 2003, 393.

[26] Tsai C.L., YANG C.C., Lin M.S., HuAng K.S., The surface emg activity analysis between badminton smash and jump smash, ISBS - Conference Proceedings Archive, 2005, 483-486.

[27] Tsai C.L., Hsueh Y.C., PAN K.M., Chang S.S., Biomechanical analysis of different badminton forehand overhead strokes of Taiwan elite female players, ISBS - Conference Proceedings Archive, 2008, 719-722.
[28] Waddell D.B., Gowitzke B.A., Biomechanical principles applied to badminton power strokes, ISBS - Conference Proceedings Archive, 2000.

[29] Wagner H., Pfusterschmied J., Tilp M., Landlinger J., VON DUVILlard S.P., MüLler E., Upper body kinematics in team handball throw, tennis serve, and volleyball spike, Scand. J. Med. Sci. Spor., 2014, 24 (2), 345-354.

[30] Werner S.L., Guido Jr J.A., Stewart G.W., Mcneice R.P., VANDYKE T., JONES D.G., Relationships between throwing mechanics and shoulder distraction in collegiate baseball pitchers, J. Shoulder Elb. Surg., 2007, 16 (1), 37-42.

[31] Zhang Z., Li S., Wan B., Visentin P., JiAng Q., Dyck M., Li H., Shan G., The influence of X-factor (trunk rotation) and experience on the quality of the badminton forehand smash, J. Hum. Kinet., 2016, 53 (1), 9-22. 